\title{
The Hakemite Tables of Ebn Jounis.
}

\section{By J. H. Reynolds.}

() Nov. 8, 1929, the last occasion on which the late Dr. Knobel attended a meeting of the Royal Astronomical Society, he presented to the Society a rare copy of the Hakemite Tables of Ebn Jounis, translated by "Citoyen" Caussin, professor of Arabic in the College of France, An XII de la Republique (=A.D. 1804). This valuable and interesting book throws a strong light on the high standard of accuracy in observation which had been reached by the Arab and Egyptian astronomers. At the time the tables were compiled (circa A.D. 1000) the semi-barbaric European nations were seldom at peace, either internally or externally, and all learning had suffered grievously from civil disturbances and the neglect and ignorance of the ecclesiastical foundations. In the Near East at that time astronomy and mathematics were considered to be an intrinsic part of the education of Mohammedan princes, and astronomers were therefore often attached to their courts. It is true that astrology and prognostics were the vera causa of this princely interest in the majority of cases, but that did not make the observational work of the Arab astronomers any less valuable in the ultimate event.

The original Arabic MS. from which the translation was made was, and still is, in the library of the University of Leyden, and it was lent to the Institut de France by the Dutch Government of the time. There is no record of how it came into the possession of the University of Leyden, but it was undoubtedly a copy of the original MS., transcribed about seven hundred years ago. There were several copies of the work originally in the library of the Alhazar University in Cairo, and it is possible that the Leyden MS. may be part of one of these, as many of the MSS. of the library were scattered and destroyed in the repeated conquests and sackings of Cairo in the Middle Ages. Caussin was of the opinion that the Leyden MS. contained about half of the original observations made by Ebn Jounis, and that there were two volumes.

Besides a long preface, the whole work originally contained eighty-one chapters, the title of each being given in the introduction. The twenty-second chapter is the last which appears in the Leyden MS., so the greater part of the work is unfortunately totally lost to us. The titles of some of the chapters sound sufficiently modern : for example, Chap. iii., On mean time and true (solar) time-how to convert one into the other, and different methods employed by various authors of tables ; Chap. x., On chords of a circle, on sines, and how to use them in calculating from the tables ; Chap. xi., On the obliquity of the ecliptic, on the dimensions of the earth's shadow, and tables relative thereto ; Chap. Ixxvii., On radiation from the stars, according to general opinion. Other chapters introduce us to matters which, fortunately, do not affect us to-day: Chap. xv., On ares diurnal and nocturnal; on fractions of the hour by day and night ; on equal and unequal time. Chap. xvi., On the twelve houses of the sun. Chap. Ixxxi., On the revolutions of the years of the earth, and on nativities.

Caussin's translation only includes the introduction and the fourth, fifth, and sixth chapters, so there is still ample work to be done in the way of translation by Arabic scholars.

An Arabic MS. in the French Bibliothèque Nationale contains the tables of the sun and moon by this author, amongst various tables taken from the works of the other astronomers. These tables form part of a work entitled "Al zij Almosthal ali", which seems to have been composed in the fourteenth century of our era. Caussin remarks: "Le titre encore plus récent qui est à la tête, l'attribue à Ebn Jounis, apparemment pour lui donner plus de prix. C'est une supercherie dont les Orientaux se servent quelquefois vis-à-vis des Européens qui achètent des manuscrits sans les lire".

Ebn Jounis came of an ancient Arab-Egyptian family. Like many of his contemporaries, he was something of a poet and a musician, as well as an astronomer. The date of his birth is unknown, but he died on May 31, 1008. There seem to have been two editions of his astronomical tables, one written about 990, in the reign of the Caliph Aziz, to whom it was dedicated, and the second, a corrected and extended series of observations, being written in the reign of his son Hakem, and dedicated to him, whence the title of the Hakemite Tables is derived.

Ebn Jounis's observatory was on a rocky spur of the Mokattam Hills near Fustat (Old Cairo), at a place called Birket Alhabash, originally a reservoir on the east side of the Nile, afterwards turned into a garden. This was probably near the old aqueduct to the citadel built by Nasir in 1311, parts of which are still standing.

In one of the Arabic texts there is mention of observations at 'Holwon', to which Caussin adds the following note: "Holwon, quelques lieues au-dessous du Caire, sur le bord oriental du Nil ". This is without doubt the present town of Helwân, near which the modern observatory was erected in 1904 under the supervision of Sir Henry Lyons.

Ebn Jounis presupposed in the table a knowledge of Ptolemy's work, and his first aim was to assemble all that related to practical observation, calculation, and the use of tables. His ultimate object was to correct the tables current in his time, and his own observations were therefore of great assistance in the new tables. A quarter of the MS. is devoted to the chronology of the Hegira, and is omitted in the French translation, as it is comparatively unimportant. The commencement of the preface is worth translation and reproduction here:

"In the name of Allah, the compassionate, the merciful! The study of the heavenly bodies is not unconnected with religion. By this alone can be known the hours of prayer; the time of sunrise, when he who observes a fast should abstain from drinking and eating; the end of the evening twilight, the term of vows and religious obligations; the time of the eclipses, of which a man should be forewarned, so that he may prepare himself with the special prayer proper for such an occasion.

"The same study is necessary for turning in prayer always towards the Kaaba (Mecca), for determining the commencement of the months, for knowing certain doubtful days, the time for seeding, the budding of the trees, the picking of fruits, the position of one place with regard to another, and for journeying in a definite direction without straying.

"The movement of the heavenly bodies being thus allied to many divine percepts, and the observations made in the time of the Caliph Almamoun [at Bagdad] being already out of date, and containing errors similar to those made aforetime by Archimedes, Hipparchus, Ptolemy, and others, our Lord and master the Commander of the Faithful Abou Ali Almansour al imam al hakem bams Allah (May God bless him, his virtuous ancestors, and his noble descendants), has ordered me to observe anew the heavenly bodies whose movement is more or less in accord, and many 
of those whose progress is slow compared with the existing tables.

"First of all I assured myself of the excellency of the instruments with which I made my observations. I constructed them with greatest care, and divided them with the finest accuracy I could command. I spent much time in examining them and verifying their divisions. I compared them one with the other to assure myself of their reliability; and when I had found with certainty the places of the planets, I used, in order to determine their mean motions, the observations of the ancients, since it is in this way alone that such a correct determination can be made.'

The principal instruments used by Ebn Jounis were the armillary sphere and the azimuth circle. The larger the diameter of these, the greater the accuracy with which they could be divided. Unfortunately, no details are given as to their dimensions and construction, so we have to fall back on descriptions of such instruments constructed at Cairo after the death of Ebn Jounis and contained in Caussin's notes.

The armillary sphere was a series of rings, the outer and principal one representing the meridian. Then came a movable declination ring pivoted on the poles, containing on its inner edge two other pivots $23^{\circ}$ from the poles, and on these pivots were fixed two other rings at right angles to each other, representing the ecliptic and colures. Still another sliding inner ring with sights at the ends of a diameter enabled readings to be taken both in latitude and longitude. These were made up to $2 \mathrm{ft}$. in diameter and probably more, as the azimuth circle constructed by the order of Alfadel a hundred years later was 200 inches in diameter.

Numerous references are made in the introduction and Chap. iv. to the "Verified Table". This table was compiled by order of the Caliph Almamoun at Bagdad about fifty years before Ebn Jounis worked out his own Tables. Several astronomers were engaged in this compilation, the principal being Jahia ebn Aboumansour. An Arabic MS. of this Verified Table was, and presumably is now, in the library of the Escurial.

Ebn Jounis devotes the whole of Chap. iv. to a comparison between recent observation and calculation by the Verified Table, especially with regard to eclipses of the sun and moon. $\mathrm{He}$ was specially critical of tables of the sun's longitude, which he found to be largely in error. He points out that the armillary sphere of Jahia ebn Aboumansour was only divided to $10^{\prime}$ of arc, and was not, therefore, of the accuracy required for close determinations of the sun's place. As an example of the refinement of accuracy attempted by the Arab astronomers, Ebn Jounis cites results obtained for the mean motion of the sun in a Persian year of 365 days. The sons of Moussa ebn Shaker at Bagdad gave this as $359^{\circ} 45^{\prime}$ $39^{\prime \prime} 58^{\prime \prime \prime} 2^{\prime \prime \prime \prime}$ ! The division of the second into sixty thirds, and that again into sixty fourths, and on occasion even to fifths, must come as a great surprise to present-day astronomers, for a fifth was only equal to $0 \cdot 0004 "$, a quantity representing less than probable instrumental error even to-day. Of course, the figures given were simply obtained by continuing division.

A list of conjunctions of the planets with each other and with the 'Lion's Heart' (Regulus) are given with considerable detail. One observed by Habash at Bagdad on Oct. 10, A.D. 864, was that of Mars and Venus in Virgo, so close as to appear one planet. "We have obtained their conjunction in this manner in the table Alshemashia by adding to the epicycle of Venus, and to the mean motion of the sun in the table $4^{\circ} 30^{\prime}$; next deducting from the epicycle of Mars $30^{\prime}$, and deducting the result from the mean motion of the sun."

Some partial eclipses of the sun visible in Cairo were observed with great interest by Ebn Jounis and his friends, who assembled at the Mosque of Aboufaafer Almagrebi for the purpose. One on Dec. 12, A.D. 977, was evidently a great astronomical occasion. The names of many of those in attendance were given, of whom he says: "These persons were instructed without being versed in the practice of judiciary astronomy (prognostics) ". The eclipse was first seen when the sun was between $15^{\circ}$ and $16^{\circ}$ above the horizon. Its greatest phase was estimated at 8 digits (twelfths of the diameter) in magnitude. "When the sun seemed to regain all its brilliancy I found its altitude to be about $33^{\circ} 20^{\prime}$, all being in agreement as to the end of the eclipse." Next appears a list of determinations of the vernal and autumnal equinoxes, made by various astronomers, commencing with one by Ptolemy in the third year of the reign of Antoninus Pius, at Alexandria. Many observations by Arab astronomers at Bagdad and Damascus, from A.D. 830 to A.D. 851, appear also in the text.

Chap. v, contains various determinations of the sun's mean motion in the Persian year of 365 days, almost all of them being in agreement with a value of $359^{\circ} 45^{\prime} 39^{\prime \prime}$, differing only in thirds. All of the astronomers arrived at their results by dividing the number of solar revolutions by the number of Persian years which had elapsed between the time of their observations and the original observation of Hipparchus. By the same method Ebn Jounis arrived at a slightly larger value- $359^{\circ} 45^{\prime} 40^{\prime \prime} 3^{\prime \prime \prime} 44^{\prime \prime \prime \prime}$. He is especially interested in various estimates of the position of the "Lion's Heart'. "I am going to give particulars of these differences, so that those who wish to know the science of calculation and observation of the heavenly bodies, by comprehending every difficulty and by seeing how much trouble is involved in arriving at the truth, may be more disposed to excuse errors which escape the notice of persons who give themselves up to this kind of study; and Allah conducts whom he will in the path of exactitude."

The differences in the positions of Regulus were found to range from $3^{\prime}$ to $33^{\prime}$ for the same year by interpolation from various observations made in previous and subsequent years. The Arab astronomers who contributed the results are mentioned individually and their calculated places given in detail.

Chap. vi. is entitled: "On the mean motions of the Verified Table, on its equinoxes, and on the position of its apogees: on the mean motions of the present Table, on its equations and its apogees ". This chapter consists entirely of comparisons between various determinations by Ptolemy and others of the mean motions and other elements of the sun, moon, and planets and Ibn Jounis' own results. It is scarcely of sufficient general interest to quote extracts here. Caussin had evidently intended to translate and publish the rest of the Leyden MS., but this unfortunately he never accomplished. $\mathrm{He}$ ends the volume by giving various small extracts from other Arabic astronomical MSS., with a computation based on the Tables.

All the way through, the actual Arabic text is given on one page with the French translation on the other. The text is fully annotated with references to Arab astronomers, their instruments, and their methods of observation. Evidently, Caussin was a master both of classical written Arabic and Arab literature, and his work deserves the grateful appreciation of scientific historians. 